\title{
Interlaminar Fracture Energy of Laminates Made of Thermoplastic Impregnated Fiber Bundles
}

\author{
H. WiTTICH AND K. FRIEDRICH \\ Technical University Hamburg-Harburg \\ Polymer \& Composites Group \\ 2100 Hamburg 90 \\ West Germany
}

\begin{abstract}
Interlaminar mode I- and II-fracture energy measurements (in terms of the strain energy release rate) were carried out with different laminates of a glass fiber/thermoplastic PA 12and aramid fiber/PA 12-composite system. Specimens were prepared from fiber bundles interspersed with polymer powder and a polymer sheath around them. The results, obtained from two different test procedures and data reduction methods, reflect a good interlaminar fracture toughness of the different laminates. This can be attributed to the large damage zone size due to the tough matrix and a big amount of fiber bridging, which is highlighted by micrographs achieved with SEM-analysis.
\end{abstract}

\section{INTRODUCTION}

D UE TO THE physical and chemical restrictions of thermosetting resins, thermoplastic polymers as matrices for high performance composites, are becoming more and more important $[1,2]$. One reason for this is the good hot/wet properties combined with very good toughness [1] and better damage tolerance [2] than those of thermosetting matrix composites. Especially, the better resistance against interlaminar crack propagation of high performance composites with a thermoplastic matrix can be considered to be an important fact which may give rise for further industrial application of this material group.

Another reason for the growing importance of thermoplastic matrices is the better processability (thermoformability, weldability, shorter curing or processing cycles, unlimited shelf life) [3]. Also, a large number of different intermediate material forms of carbon (CF), aramid (AF) and glass fiber (GF) reinforced thermoplastics are now available [4]. Since melt impregnation of the thermoplastics is rather difficult due to their high melt viscosity, the initial techniques involved solution impregnation. Newer methods to build thermoplastic matrix composites include film stacking, co- or intermingling of fibers, and powder impregnation [5], as shown in Figure 1.

Journal of Thermoplastic Composite Materials, Vol. 1-July 1988 

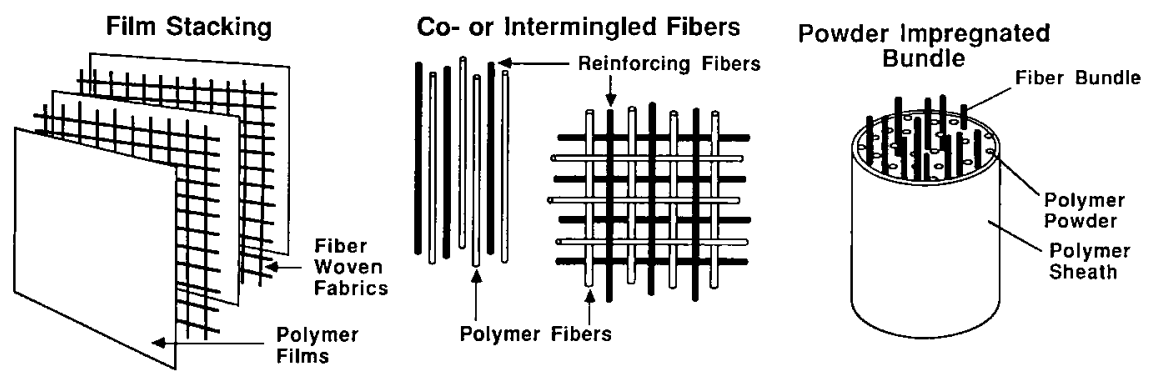

Figure 1. Intermediate material forms for thermoplastic composites.

In the present article the latter intermediate form $\left(\right.$ FIT $\left.^{(3)}\right)$, supplied by Atochem (France), was used to manufacture flat test specimens. The objective was to investigate the critical strain energy release rate in mode I and mode II loading conditions of glass or aramid fiber continuously reinforced polyamid (PA) 12 composites.

\section{EXPERIMENTAL}

\section{Materials}

The FIT ${ }^{\circledR}$ material used in the experiments consisted of fiber-rovings of about 6000 fibers with interspersed polyamide 12 matrix powder (PA 12), and a thin extruded PA 12 sheath around the whole bundle.

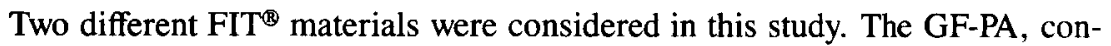
sisting of 70 weight $\%$ (w/o) glass fibers (2400 TEX; diameter: $22 \mu \mathrm{m}$ ) and 30 w/o PA 12 (fiber volume fraction is $49 \%$ ), and the AF-PA, consisting of 47 w/o aramid fibers (KEVLAR 49; diameter: $12 \mu \mathrm{m}$ ) and 53 w/o PA 12 (fiber volume fraction is $38 \%$ ).

\section{Manufacturing}

The "prepreg" sheets of about $0.4 \mathrm{~mm}-0.5 \mathrm{~mm}$ were made by unidirectionally placing 4 glass or 7 aramid fiber bundles per $\mathrm{cm}$ within a steel mold as shown in Figure 1. Consolidation was obtained by placing the filled mold in a heated press. The procedure involved the following steps:

(a) Heating up to $195^{\circ} \mathrm{C}$ and then applying a compressive pressure of $0.75 \mathrm{MPa}$ (in the case of AF) or 3.0 MPa (GF) over a period of 20 minutes. Higher temperatures and/or pressures resulted in a large amount of unoriented fibers because the matrix (in the case of the thin $\mathrm{AF}$, also fibers) squeezes out of the mold.

(b) Cooling down of the consolidated sheet under pressure within 5 minutes.

For easy releasing from the mold, steel foils were placed between the mold and the sheet, which also results in a smooth surface (see Figure 2). 


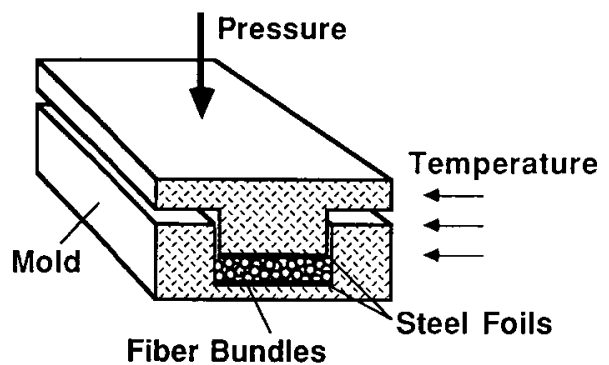

Figure 2. Preparation of prepregs from thermoplastic impregnated fiber bundles.

The laminates were made using these sheets following the same procedure to produce different lay-ups of 8 sheets each, a) $[0]_{s}$, b) $[0,90,0,90]_{s}$, c) $[90,0,90,0]_{s^{-}}$ laminates.

A small capton film was placed between the 4th and 5th layer at one end of the laminate during manufacturing to obtain a starter crack. The specimens were then cut out using a diamond saw. All specimens were $w=10 \mathrm{~mm}$ wide and $1=100 \mathrm{~mm}$ long as depicted in Figure 3 .

\section{Mode I-Tests}

Mode I-tests were performed at room temperature by using the DCB (double cantilever beam) test procedure with several load and unload circles as described in [6]. As an alternative a test procedure without unloading but stopping the machine until the crack arrests at a definitive crack-length was used (Figure 4). To load a specimen, aluminum hinges were bonded at the end of the starter crack. A natural starter crack was propagated some millimeters ahead of the foil by

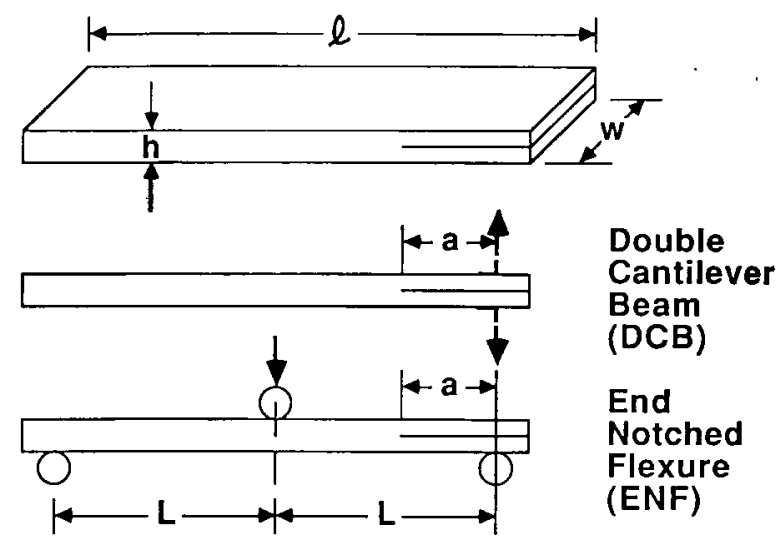

Figure 3. Specimens for interlaminar fracture studies. 

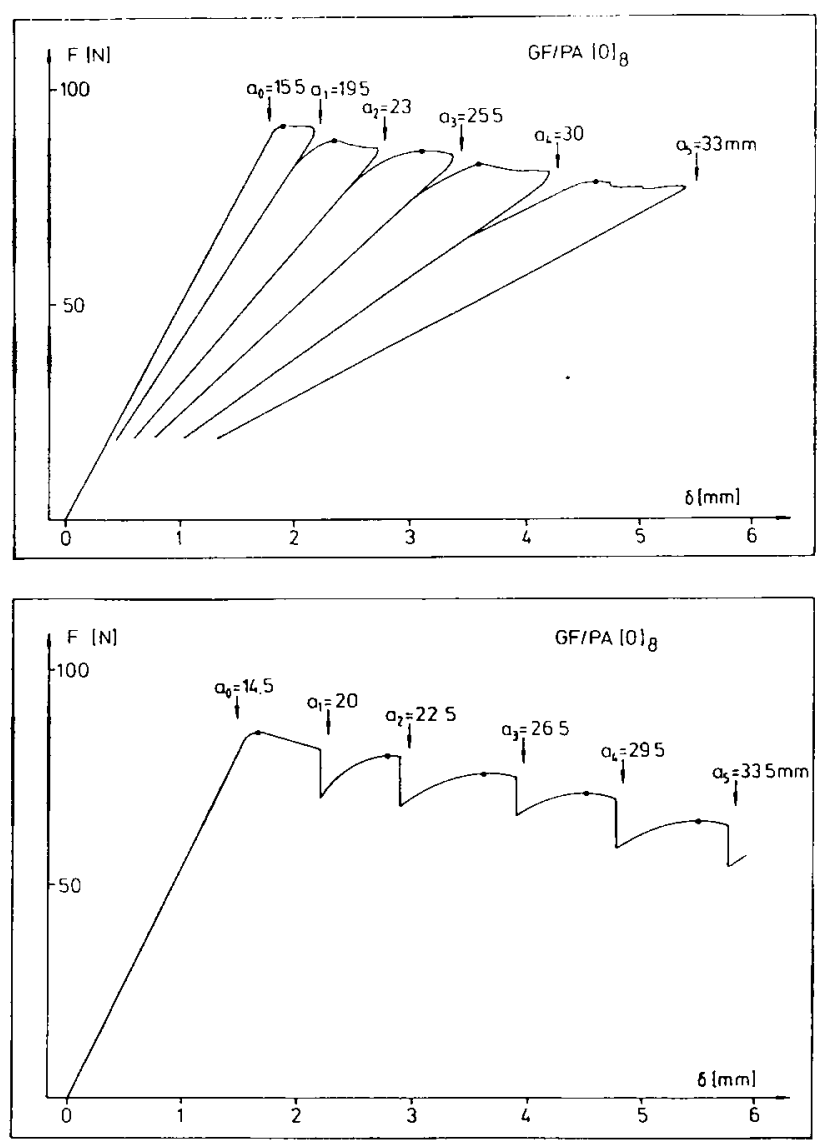

Figure 4. Load-displacement-diagrams for test-procedure $A$ (with load-unload cycles) and $B$ (with stopping the displacement until the crack arrest).

opening the crack. The crosshead speed used in the Zwick 1445 static testing machine was $1 \mathrm{~mm} / \mathrm{min}$. Load and displacement were continuously recorded and the actual crack lengths were marked on these records.

From these data the mode I-fracture energy $\left(G_{I c}\right)$ was calculated using the compliance as well the area method based on the elastic beam theory as described in [6]:

$$
\begin{gathered}
G_{I c}=F_{c}^{2} / 2 w \cdot d C / d a \\
C=\partial / F=2 / 3 \cdot a^{3} / E I \\
G_{I c}=\left(F_{c(n-1)} \partial_{n}-F_{c_{n}} \partial_{(n-1)}\right) / 2 w\left(a_{n}-a_{(n-1)}\right)
\end{gathered}
$$


where

$F_{c}=$ critical load (maximum in the load displacement curve, point marked in Figure 4)

$w=$ specimen width

$C=$ compliance

$\partial=$ displacement

$a=$ crack length

$E=$ Youngs modulus

$I=$ moment of inertia

$n=$ integer

\section{Mode II-Tests}

Mode II-tests were performed using the ENF (end notched flexure) test procedure [6]. Even using a crosshead speed of $0.5 \mathrm{~mm} / \mathrm{min}$ the crack propagation is unstable and the crack arrested at the center loading point.

From the load displacement records (Figure 5) the mode II-fracture energy $\left(G_{I C}\right)$ was calculated by Equation (4) [6]:

$$
G_{I I c}=9 F_{c}^{2} C a^{2} / 2 w\left(2 L^{3}+3 a^{3}\right)
$$

where

$L=$ the distance between the middle loading pin and the outer pins

It should be noted that in the case of AF reinforced test specimens, aluminum

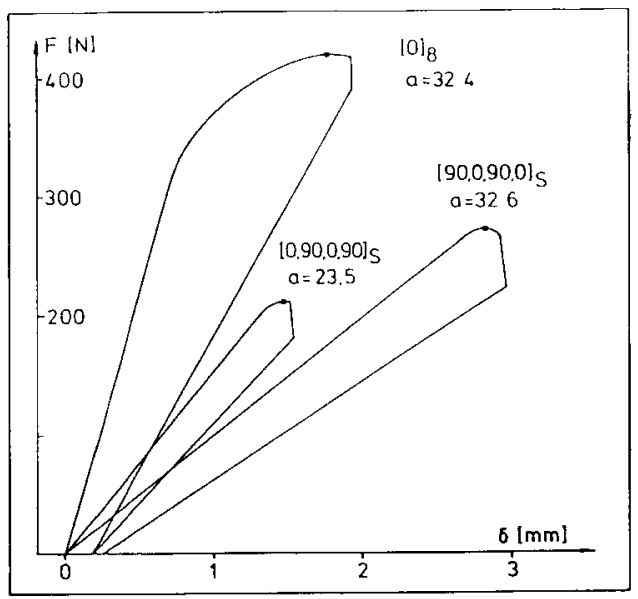

Figure 5. Load-displacement-diagram. 
backbone stiffeners, bonded to the top and bottom of the beam, were used to prevent them from transverse cracking before delamination occurred. In mode II loading conditions the bond was not strong enough, so only in that case no results were obtained.

\section{RESULTS AND DISCUSSION}

\section{Mode I}

To evaluate the influence of the different test procedures used (A: load-unload cycles, B: increasing load with several stops), GF/PA-specimens with a lay-up like $[0]_{8}$ and $[90,0,90,0]_{s}$ were tested. According to Reference [6], the data of test procedure A were analyzed with the compliance and the area method. The results are shown in Figure 6 (each scatter bar resulted from 5 specimens).

Nevertheless the crack propagates in both laminates between $0^{\circ}$-layers, the stiffer specimens $\left([0]_{8}\right)$ result in higher $G_{I c}$-values. This also can be seen later on with the aluminum stiffened specimens.

The results of the area and compliance data reduction method are almost the same, but the area method results are smaller in the case of the $[0]_{8}$-laminate and bigger in the case of the $[90,0,90,0]_{s}$-laminate than the compliance values. The lay-up affects the $G_{I c}$-value obtained by the area method not as much as in the case of the compliance method.

A more pronounced difference becomes obvious upon comparing the two test procedures. Crack arresting under load (B) results in higher $G_{I c}$-values than unloading (A).

Since the AF/PA specimens also show transverse cracks during the test, they were stiffened by aluminum backbones. These specimens were tested following the test procedure B. To compare this data with the GF/PA material, these specimens were also stiffened using aluminum backbone. Figure 7 shows the results for the $0^{\circ}$ - and $90^{\circ}$-crack propagation directions to fiber orientation.

All specimens with $90^{\circ}$-layers in the fracture plane have lower $G_{I c}$-values than the specimens with $0^{\circ}$-layers in the fracture plane, although the effect is not so drastic in the case of the unstiffened GF/PA specimens.

From the SEM-analysis, the micrographs show that the damaged zone is spread over several fiber diameters (Figure 8 ). This lead to high energy absorbtion during crack propagation due to ductile deformation in the relative big damage zone and a large amount of fibers bridging the crack (Figure 9); i.e. also fiber cracking is a main energy absorbing mechanism, but only in the case of $0^{\circ}$ layers in the fracture plane. Due to the smaller diameter there are more aramid fibers per cross section than glass-fibers; also aramid fibers have a better flexural and tensional response. As a result, the AF-reinforced specimens showed higher $G_{I c}$-values. The big ductile deformation of the PA 12 matrix can be seen in the crack surface micrographs (Figure 10). This is also known from previous tests with a carbon fiber/PA 12-composite out of the same intermediate material [7] and other tough matrices like PEEK, which give 10 times higher $G_{I c}$-values than standard CF/Epoxy composites. 


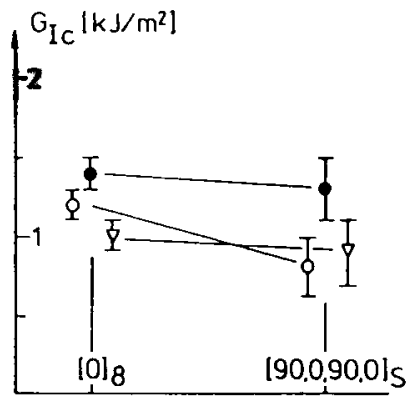

\begin{tabular}{|c|c|c|}
\hline Mode I & \multicolumn{2}{|l|}{$\begin{array}{l}\text { GF/PA 12 } \\
\text { unstiffened }\end{array}$} \\
\hline \multicolumn{3}{|c|}{ dotared.meth. } \\
\hline$\nabla$ & area & testproc. \\
\hline & compliance & A \\
$\bullet$ & compliance & B \\
\hline
\end{tabular}

Figure 6. Results of the two different test-procedures (A and $B$ ) and data reduction methods (area and compliance method).

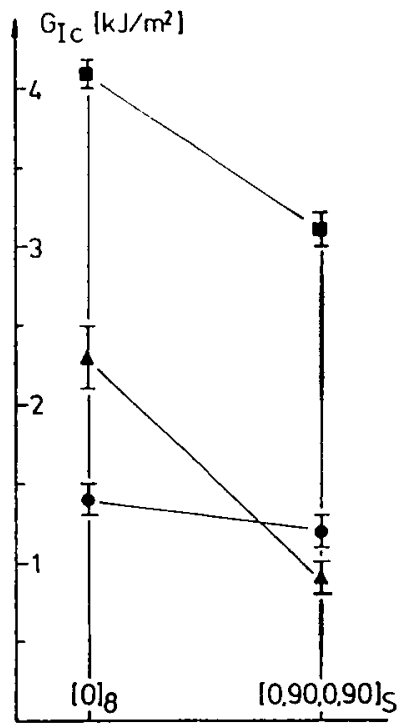

\begin{tabular}{|c|cc|}
\hline Mode I & \multicolumn{2}{|c|}{$\begin{array}{l}\text { testprocedure B } \\
\text { compliance method }\end{array}$} \\
\hline & fiber & stiffened \\
\hline - & AF & yes \\
- & GF & yes \\
- & GF & no \\
\hline
\end{tabular}

Figure 7. Results of the stiffened specimens in comparison to the unstiffened GF/PA specimens. 

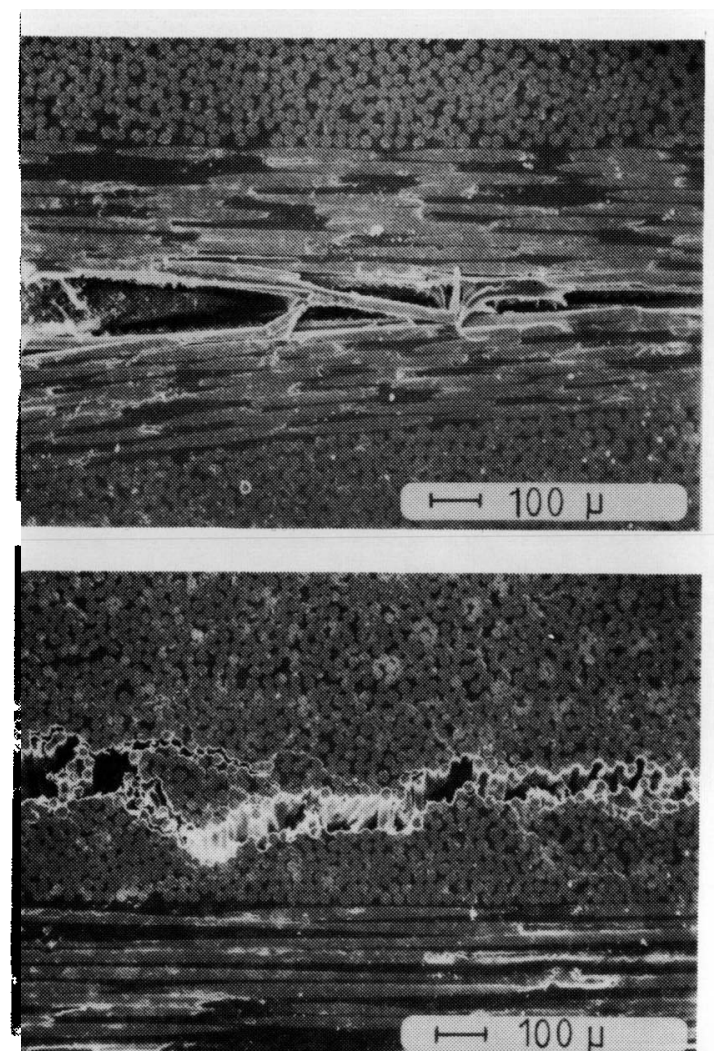

Figure 8. Micrographs of the crack tip with fracture planes in $0^{\circ}$-layers and $90^{\circ}$-layers.

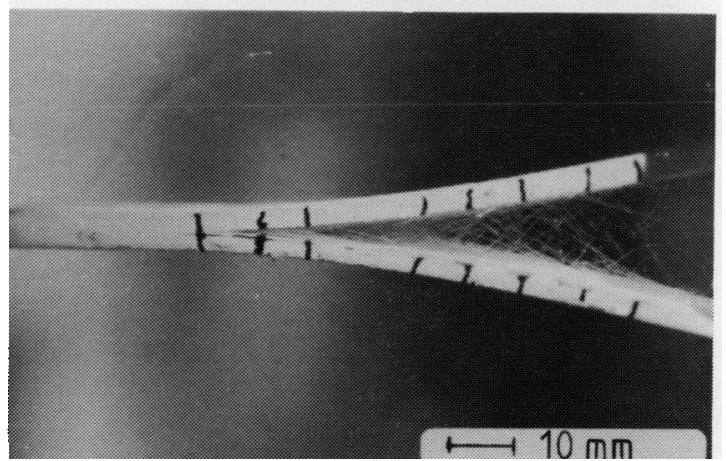

Figure 9. Photograph of a GF/PA specimen showing the big amount of fiber bridging. 


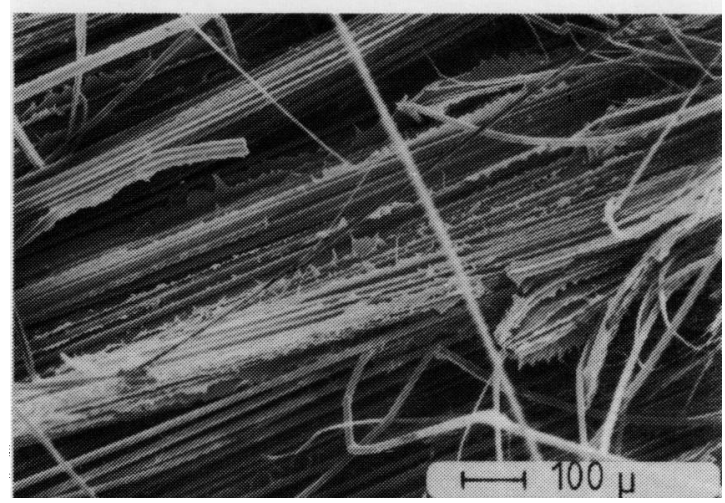

Figure 10. Crack surface of an AF/PA specimen.

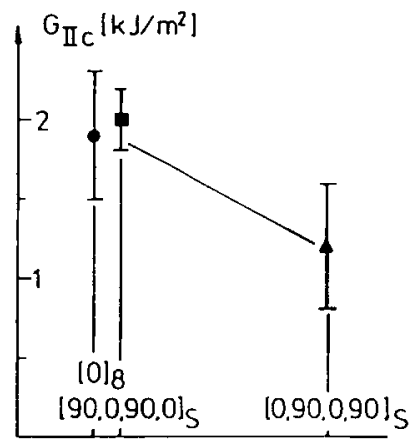

\begin{tabular}{|c|c|}
\hline Mode II & $\begin{array}{l}\text { GF/PA } 12 \\
\text { stiftened } \\
\text { compliance }\end{array}$ \\
\hline & $\left.10\right|_{8}$ \\
\hline a & $\begin{array}{l}{[90,0,90,0]_{\mathrm{S}}} \\
{[0,90,0,90]_{\mathrm{S}}}\end{array}$ \\
\hline
\end{tabular}

Figure 11. Results of the mode II-tests.

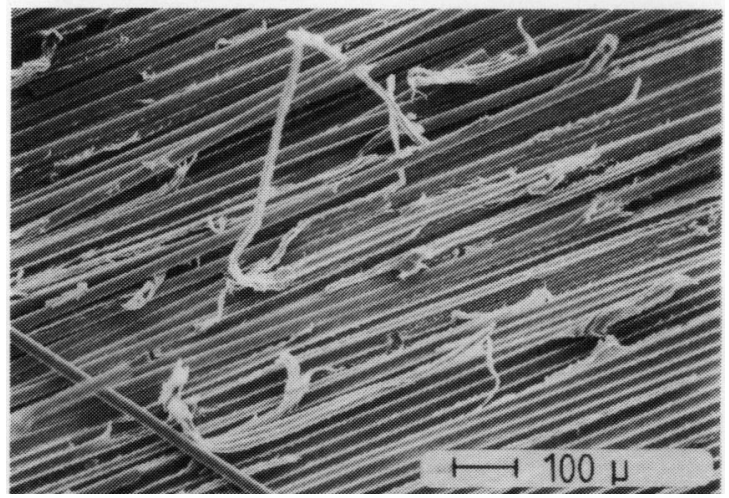

Figure 12. Crack surface of a GF/PA specimen in mode II. 


\section{Mode II}

The mode II-strain energy release rate for the GF reinforced specimens is shown in Figure 11.

Most of the $G_{I I c}$-values are somewhat higher than the $G_{I c}$-values, although the difference for the $90^{\circ}$ fiber oriented fracture plane is not as big as the $0^{\circ}$ one. The inplane shear (mode II) fracture mode shows a different matrix deformation (Figure 12) than in mode I. Almost no fiber bridging occurs during crack propagation. Only occasionally there are some cracked fibers, which were pulled out of the surrounding matrix.

From literature [8] it is known that in this fracture mode the crack tip stresses are lead along the fibers, resulting in a larger damage zone size ahead of the crack tip than in mode I. However, this is only true for crack planes between $0^{\circ}$-layers. In crack planes between $90^{\circ}$-layers the sliding of the two beams is hindered by the ripping of the fibers.

\section{CONCLUSIONS}

This investigation shows that continuous fiber bundles, interspersed with fine thermoplastic PA 12 powder and surrounded by a sheath of the same polymer, can be consolidated into different laminate forms.

The strain energy release rate in mode I varies between $2.3 \mathrm{~kJ} / \mathrm{m}^{2}$ and $0.8 \mathrm{~kJ} / \mathrm{m}^{2}$ for the glass fiber and $4.1 \mathrm{~kJ} / \mathrm{m}^{2}$ and $3.1 \mathrm{~kJ} / \mathrm{m}^{2}$ for the aramid fiber reinforced composite system. The actual results depend on the stiffness, fiber orientation, test procedure and data reduction method.

Mode II energy release rate for the tested glass fiber reinforced PA 12 vary between $2.0 \mathrm{~kJ} / \mathrm{m}^{2}$ and $1.2 \mathrm{~kJ} / \mathrm{m}^{2}$ in dependence on the stiffness and fiber orientation.

As a final comment it should be noted that the data presented in this paper are to be considered as preliminary results, and emphasis should be given to their qualitative nature, rather than forming a quantitative data base. The reasons for this statement are 1) a very limited amount of material available at the time of this study, 2) a rather primitive consolidation procedure for the preparation of the laminates, and 3) a strict limitation in specimen geometry, which did not allow to stay within the recommended dimensions. The data can, however, be seen as trends of what can be expected from these particular fiber/matrix combinations.

\section{ACKNOWLEDGEMENTS}

This study was supported by a Research Cooperation Contract between the Bulgarian Government and the German BMFT (Bundesministerium für Forschung und Technologie of the FRG). The support of intermediate material received from ATOCHEM, Paris la Defense, France, is gratefully acknowledged.

\section{REFERENCES}

1. Stolze, R. "Verstärkungsfasern und Matrixmaterialien für Hochleistungsverbundwerkstoffe," Kunststoffe 77, 11:1157 (1987). 
2. Brandt, J. and H. Richter. "Hochleistungsverbundwerkstoffe mit Thermoplastischer Matrix," Kunststoffe 77, 1:40 (1987).

3. Growe, S. M. and D. Short. "Fabrication Processes for Continuous Fibre-Reinforced Thermoplastics," High Tech-The Way into the Nineties, K. Brunsch, H. D. Gölden, C. M. Herkert, eds., Amsterdam:Elsevier Science Publishers (1986).

4. Neise, E. Praktische Erfahrungen bei der Verarbeitung Gewebeverstärkter Thermoplaste, Vortrag 21. AVK-Tagung Mainz (November 1987).

5. Stolze, R. "Aramid and Carbon Fibre Reinforced Thermoplastics: Opportunities in Comparison with Thermosetting Plastics, Need for New Manufacturing Processes," Report on the 25th Intern. Man-Made Fibres Congress Dornbirn (September 24-26, 1986).

6. Carlsson, L. A. and R. B. Pipes. Experimental Characterization of Advanced Composite Materials, New Jersey:Prentice-Hall (1987).

7. Friedrich, K., T. Gogeva and S. Fakirov. "Thermoplastic Impregnated Fiber Bundles: Manufacturing of Laminates and Their Fracture Mechanical Characterization," Comp. Sci. Technol, 33:97 (1988).

8. Corleto, C., W. Bradley and M. Henriksen. "Correspondence between Stress Fields and Damage Zones Ahead of the Cracktip of Composites under Mode I and Mode II Delamination," Proceedings of the 6th ICCM \& 2nd ECCM, 20-27 July, 1987, London, 3(3):378. 